\title{
Sharing for science: High-resolution trophic interactions revealed rapidly by social media
}

\author{
Robin A Maritz ${ }^{\text {Corresp., } 1}$, Bryan Maritz ${ }^{1}$ \\ ${ }^{1}$ Department of Biodiversity and Conservation Biology, University of the Western Cape, Bellville, South Africa \\ Corresponding Author: Robin A Maritz \\ Email address: maritzrobin.a@gmail.com
}

Discrete, ephemeral natural phenomena with low spatial or temporal predictability are incredibly challenging to study systematically. In ecology, species interactions, which constitute the functional backbone of ecological communities, can be notoriously difficult to characterise especially when taxa are inconspicuous and the interactions of interest (e.g., trophic events) occur infrequently, rapidly, or variably in space and time.

Overcoming such issues has historically required significant time and resource investment to collect sufficient data, precluding the answering of many ecological and evolutionary questions. Here, we show the utility of social media for rapidly collecting observations of ephemeral ecological phenomena with low spatial and temporal predictability by using a Facebook group dedicated to collecting predation events involving reptiles and amphibians in sub-Saharan Africa. We collected over 1900 independent feeding observations using Facebook from 2015-2019 involving 83 families of predators and 129 families of prey. Feeding events by snakes were particularly well-represented with close to 1100 feeding observations recorded. Relative to an extensive literature review spanning 226 sources and 138 years, we found that social media has provided snake dietary records faster than ever before in history with prey being identified to a finer taxonomic resolution and showing only modest concordance with the literature due to the number of novel interactions that were detected. Finally, we demonstrate that social media can outperform other citizen science image-based approaches (iNaturalist and Google Images) highlighting the versatility of social media and its ability to function as a citizen science platform. 
1 Sharing for Science: High-resolution trophic interactions revealed rapidly by social media

2

3 Robin A. Maritz ${ }^{1}$ and Bryan Maritz ${ }^{1}$

4

$5{ }^{1}$ Department of Biodiversity and Conservation Biology, University of the Western Cape,

6 Bellville, Western Cape, South Africa

7

8 Corresponding Author: Robin A. Maritz ${ }^{1}$

9 Email Address: maritzrobin.a@gmail.com

10

11

12

13

14

15

16

17

18

19

20

21

22

23

Peer] reviewing PDF | (2020:03:47047:1:1:NEW 9 Jun 2020) 


\section{Abstract}

25 Discrete, ephemeral natural phenomena with low spatial or temporal predictability are incredibly challenging to study systematically. In ecology, species interactions, which constitute the

27 functional backbone of ecological communities, can be notoriously difficult to characterise 28 especially when taxa are inconspicuous and the interactions of interest (e.g., trophic events) 29 occur infrequently, rapidly, or variably in space and time. Overcoming such issues has 30 historically required significant time and resource investment to collect sufficient data, 31 precluding the answering of many ecological and evolutionary questions. Here, we show the utility of social media for rapidly collecting observations of ephemeral ecological phenomena with low spatial and temporal predictability by using a Facebook group dedicated to collecting predation events involving reptiles and amphibians in sub-Saharan Africa. We collected over 1900 independent feeding observations using Facebook from 2015-2019 involving 83 families of predators and 129 families of prey. Feeding events by snakes were particularly wellrepresented with close to 1100 feeding observations recorded. Relative to an extensive literature review spanning 226 sources and 138 years, we found that social media has provided snake dietary records faster than ever before in history with prey being identified to a finer taxonomic resolution and showing only modest concordance with the literature due to the number of novel interactions that were detected. Finally, we demonstrate that social media can outperform other citizen science image-based approaches (iNaturalist and Google Images) highlighting the versatility of social media and its ability to function as a citizen science platform. 


\section{Introduction}

48 Many ecological processes exist as the net product of a large number of discrete, ephemeral

49 events. At fine spatial and temporal scales, these events are often difficult to predict, making

50 them challenging to study systematically. This challenge is particularly true for interspecific

51 biological interactions and is magnified when one or both interacting species are difficult to

52 detect, with important impacts on our understanding of the ecology of many systems. Such

53 challenges can be overcome with large investments of time and money, but these costs can be

54 prohibitive and are likely part of the reason for the remarkable absence of empirical datasets

55 characterising species interactions in ecosystems (McCann, 2007; Hegland et al., 2010; Jordano,

56 2016).

57

58 Together, the origin and development of social media and the concurrent advances in access to

59 mobile cameras represent a disruptive innovation that has changed the manner and rate at which

60 modern events are recorded and communicated. With over 3.80 billion people using social media

61 worldwide (Kemp, 2020), the synergy of social media and readily accessible mobile cameras has

62 increased the observational effort of researchers by orders of magnitude. Facebook alone has

63 more than 2.45 billion monthly active users (Facebook, 2019) making it the digital platform with

64 the largest social networking potential (Kemp, 2020). Harnessing this power has far-reaching

65 implications for understanding ecological and evolutionary processes characterised by difficult to

66 detect, discrete, transient events through the resultant increase in observation coverage and

67 depth.

68 
69 Trophic interactions, defined as interspecific interactions in which one organism consumes

70 another, form the basis for understanding processes and system characteristics as diverse as

71 energy flow, population dynamics, food web dynamics, and the evolution of behavioural,

72 morphological and physiological adaptations by predators and prey (Garvey \& Whiles, 2017).

73 Moreover, with a world experiencing climatic changes and worsening environmental conditions

74 (Vitousek et al., 1997), attention to species interactions will be crucial for understanding

75 ecosystem function and integrity (Tylianakis et al., 2008; Valiente-Banuet et al., 2014). Despite

76 their central position in ecological and evolutionary theory, the characterisation of trophic

77 interactions between species and within food webs, particularly those in which such interactions

78 are difficult to study, are often incomplete or absent (Paine, 1988; Chacoff et al., 2012; Miranda,

79 Parrini, \& Delerum, 2013; Jordano, 2016). Moreover, because certain organismal traits can

80 reduce the detection likelihood of a given trophic interaction, trophic interactions involving

81 terrestrial vertebrates (particularly non-herbivorous interactions) are underrepresented in the

82 literature (Miranda et al., 2013). In cases where such datasets exist, endotherms tend to be better

83 represented than ectotherms in trophic studies (Miranda et al., 2013) — possibly because of ease

84 of sampling or because endothermy often demands higher food intake rates. Finally, of the

85 interactions reported, organisms involved in lower-trophic-level interactions often suffer from

86 taxonomic aggregation (Polis, 1991), which can mask complex species interactions and influence

87 metrics associated with food webs, community assemblages, and interspecific competition

88 (Greene \& Jaksić, 1983; Paine, 1988; Thompson \& Townsend, 2000). Thus, a method for

89 improving the quantity and quality of trophic data collected is warranted and essential. 
91 Together, reptiles and amphibians (hereafter herpetofauna) include more than 18000 ectothermic,

92 vertebrate species globally and account for more than half of all global tetrapod diversity

93 (Pincheira-Donoso, Bauer, \& Uetz, 2013). In many terrestrial ecosystems, these animals can

94 make up a large proportion of the total abundance of vertebrates and contribute significantly to

95 the total biomass of a region (Western, 1974; Iverson, 1982; Jacobsen, 1982; Petranka \& Murray,

96 2001). Moreover, herpetofauna (mostly amphibians and squamates) often occupy intermediate

97 trophic levels providing important trophic links between small-bodied invertebrate primary

98 consumers and higher trophic levels occupied primarily by endothermic predators (e.g., Polis,

99 1991). Interestingly, snakes, a monophyletic lineage of more than 3700 species (approximately

$10010 \%$ of global tetrapod diversity; Pincheira-Donoso et al., 2013) are exclusively carnivorous and

101 potentially occupy intermediate trophic positions between many other herpetofauna and species

102 residing at higher trophic levels (FitzSimons, 1962; Greene, 1997). However, many species of

103 herpetofauna are notoriously difficult to detect and observe in the wild (Steen, 2010; Durso,

104 Willson, \& Winne, 2011; Durso \& Siegel, 2015; Lardner et al., 2015; Rodda et al., 2015), and

105 individuals of many species feed infrequently or discreetly (Greene, 1997), making the

106 systematic observation and quantification of trophic interactions incredibly challenging.

107

108 In this paper, we demonstrate the utility of a method that uses social media, specifically a

109 dedicated Facebook group, to collect images and videos of difficult to detect feeding interactions

110 involving herpetofauna in sub-Saharan Africa. We hypothesised that information regarding

111 ecological phenomena, specifically trophic interactions, can be collected at large spatial scales

112 and across diverse taxonomic clades by employing the assistance of a large network of potential

113 observers (i.e., Facebook users). First, we highlight the remarkable diversity of predator and prey 
114 interactions identified over a five-year period and provide an overview of observer statistics.

115 Next, because snake feeding events are well-represented in our dataset and are notoriously

116 difficult to observe in the wild, we tested the hypothesis that an increased quantity of data on

117 snake feeding would result in the detection of novel species interactions either due to increased

118 sampling effort or differences in detectability. Finally, we compared our dataset to data collected

119 from iNaturalist and Google Images to test whether other digital media platforms offer the

120 observational power required to detect difficult to record trophic interactions. Together, our

121 findings emphasise that previous methods have left gaps in our understanding of feeding

122 interactions involving southern African herpetofauna and to gain a more holistic understanding,

123 data collection must incorporate multiple lines of inquiry. Ultimately, our approach highlights

124 the application of Facebook to rapidly improve trophic interaction sampling coverage and depth

125 in many ecosystems and act as a model for utilising social media to study rare and difficult to

126 detect ecological events.

127

128 Materials \& Methods

129 Facebook data collection. The idea for a dedicated predation records Facebook group arose

130 amongst a small group of South African reptile researchers and enthusiasts after noticing feeding

131 observations being shared across the platform and recognising the scientific value in having a

132 place to store and later record these observations. Since then, we have administrated and curated

133 the Predation Records - Reptiles and Frogs (Sub-Saharan Africa) Facebook group

134 (facebook.com/groups/888525291183325) from its creation in August 2015 until December

135 2019. We requested that members include details such as predator and prey identity, location,

136 date, time, and observer or photographer's name when sharing an observation to the group. 
137 When information was missing, administrators or group members asked for the post to be

138 updated with the necessary details. Predator and prey identities were confirmed to the finest

139 taxonomic-level possible using a combination of locality information and key physical

140 characteristics and with support from taxon expert group members. In challenging cases, persons

141 with taxon-expertise were consulted using Facebook or via email. Observations that appeared on

142 other social media groups were incorporated in an ad hoc manner.

143

144 Literature data collection. We performed an extensive review of diet records for snake species

145 in southern African snakes (the region where most Facebook observations occurred). We

146 searched primary and grey literature sources (museum bulletins, society newsletters and

147 bulletins, wildlife magazines, and non-indexed journals) for substantiated feeding records.

148 Searches were conducted in English and the main platforms used were Google Scholar and the

149 Biodiversity Heritage Library. Interactions published without supporting details (e.g., field guide

150 descriptions) were categorised as secondary records and were not included in our final analyses.

151 In all instances prey identity was recorded with modification based on updated taxonomy. In

152 instances where only a generic name was provided, the most representative taxonomic name was

153 assigned based on geographic location. Feeding interactions in which multiple prey items of the

154 same type were ingested at once (e.g., 'three nestling chicks') were treated as a single record in

155 the database. Captive-fed observations were recorded but excluded from this study. A list of

156 literature sources used $(\mathrm{N}=226)$ and the snake species which they provide data for can be found

157 in the supporting information (Table S1).

158 
159 Data management and curation. Data were recorded manually and kept in local storage with

160 monthly back-ups to a personal cloud storage service. The data files are accessible via Figshare

161 (10.6084/m9.figshare.11920128). Images and videos from all Facebook posts have been

162 downloaded in case users delete or change the privacy settings on their uploaded media. For each

163 feeding interaction, we recorded predator/prey identity, predator/prey life stage, direction of

164 ingestion (for snake predators), interaction specifics (date, time, location), and any noteworthy

165 details. Taxonomic hierarchies were updated automatically for each predator and prey item by

166 referencing a local hierarchy database with information obtained from biodiversity databases

167 (reptile-database.org; sabap2.adu.org.za; amphibiaweb.org; gbif.org).

168

169 For Facebook records, additional information included microhabitat (e.g., tree/shrub, artificial 170 surface), type of interaction (true predation or scavenging), type of event (e.g., in situ, roadkill, 171 captured-regurgitated), share date, person who shared the record, person(s) who observed the 172 record, and post permalink. Duplicates were excluded in a semi-automated manner using a photo 173 comparison program (Duplicate Photo Cleaner, v4.7, WebMinds, Inc.). Additionally, records 174 were flagged and verified whenever an identical combination of predator, prey, and observer 175 arose.

176

177 For literature records, additional information included predator and prey snout-vent-length, 178 predator and prey mass, type of study (e.g., incidental, museum), museum voucher numbers 179 (when available), and reference. We treated any record in which a given author had published the 180 same interaction previously and did not provide any information on locality or date along with 181 the most recent account as a duplicate. 
183 Data collection from other digital media sources. We retrieved relevant observations from the 184 iNaturalist citizen science platform (iNaturalist.org) in December 2019. These included all 185 records shared on the iSpot platform (ispot.org.za) for southern Africa that were migrated to the 186 iNaturalist platform during 2017. Currently, there is no centralised method for reporting species 187 interactions on iNaturalist, but a pre-existing iNaturalist project, 'Interactions (s Afr)' 188 (inaturalist.org/projects/interactions-s-afr), gathers feeding interaction data using the observation 189 field "Eating: (Interaction)" which we used to query ("\&field:Eating: (Interaction)=") and 190 retrieve all snake feeding records in southern Africa logged onto the platform $(\mathrm{N}=77)$.

191 Uncatalogued observations were located using the following independent queries: 'feeding', 192 'eating', 'meal', 'predation', 'swallow', and 'prey'; species was set to 'Serpentes' and location 193 used was 'southern Africa' $(\mathrm{N}=25)$. Records were exported using the download observations 194 function. Duplicate interactions were identified based on iNaturalist observation numbers. The 195 crowd-sourced identification was used when available. We manually inspected images of the target species (the four most observed species in the Facebook dataset) including brown-house snake (Boaedon capensis), southern African python (Python natalensis), boomslang (Dispholidus typus), and cape cobra (Naja nivea) for additional instances of feeding that had been missed. Prey could not be identified in nine of the records because the item had already 200 been fully ingested (i.e. food bulge visible).

201

202 Google Images results were retrieved in October 2019. Searches were performed for each of the 203 four target study species using the following query: "("scientific name" | "common name")

204 (eating $\mid$ prey $\mid$ predation $\mid$ swallow $\mid$ meal $\mid$ feeding)", and all resulting images were inspected for 
205 evidence of feeding. Only images of wild feeding observations were recorded. Photos

206 documenting the same encounter were excluded manually. Observations derived from Google

207 Images were more coarsely identified as the geographic location was frequently missing, but

208 prey were identified to the finest taxonomic-level whenever possible.

209

210 Analytical approaches and comparisons. All data manipulations, graphical outputs, and 211 statistical analyses were conducted in R version 3.6.1. Code can be accessed via Figshare 212 (10.6084/m9.figshare.12287714). In all analyses, non-southern African snake species were 213 excluded. To compare the accumulation rates of Facebook and literature records, the number of 214 records in a given year was averaged with the previous $n$ years in 2-15-year windows (moving 215 average). To assess interaction novelty, duplicate interactions within the dataset for each 216 approach were removed. Then, for interactions in which the prey was identified to the species217 level (repeated at each taxonomic level) the presence of a given predator-prey interaction was 218 assigned to either literature, digital media source, or both (shared). To test for discordance 219 between the Facebook and literature dataset, Cohen's kappa coefficient $(\kappa)$ was calculated using 220 the number of unique and shared interactions (repeated at each taxonomic level) (Cohen, 1960). 221 For the comparison of prey-ratios derived from digital media sources, prey items categorised as 222 'large mammals' are species that typically exceed five kilograms.

223

\section{Results}

225 Between 2015 and 2019, we gathered a total of 1917 trophic interactions involving herpetofauna 226 using images and videos shared to the Predation Records - Reptiles and Frogs (Sub-Saharan 227 Africa) Facebook group (Figs. 1A-1L). We detected trophic interactions between 83 families of 
228 predators (across 30 orders and 9 classes) and 129 families of prey (across 51 orders and 14 229 classes) (Figs. 1A, 1G, S1). Our data encompasses observations from 18 African countries. 230 However, most feeding interactions were observed within South Africa $(75.5 \% ; \mathrm{N}=1446)$, 231 which is reflective of a geographic bias in Facebook group participation. Observations were 232 dominated by predation events involving reptiles as the predator representing $66.0 \%(\mathrm{~N}=1266)$ 233 of all trophic interactions in our dataset (Fig. 1A). Remarkably, snakes accounted for the 234 majority of these observations $(85.8 \% ; \mathrm{N}=1086)$. We detected feeding events by 85 species of 235 snakes including five of the eight families that occur in Africa.

237 In our study, there were at least 1369 unique observers who uploaded media documenting a 238 predation event. However, the actual number of observers may be larger because 48 records did 239 not explicitly state who photographed the event. On average, observers shared 1.44 instances of 240 predation $(\mathrm{SD}=1.88$, range $=32$ ). Across all observations (i.e., any class of predator), $82.0 \%$ of 241 observers reported only a single record. Whereas, $18.0 \%$ reported at least two predation events, 242 and only $0.95 \%$ of observers reported more than 10 predation events. There were 891 unique 243 observers who had documented a predation event in which the predator was a snake with an 244 average of 1.24 observations per person $(\mathrm{SD}=1.23$, range $=19)$. For instances of snakes as 245 predators, $89.5 \%$ of observers had one observation, and only $0.45 \%$ of observers have reported 246 more than 10 snake predation events. Notably, the records posted by the top four observers were 247 dominated by observations of prey in road-killed specimens or from snakes that regurgitated 248 prey items while being translocated following a request for the snake to be removed (i.e., to 249 minimise human-wildlife conflict). 
251 Our extensive literature review of southern African snake diets revealed a total of 2884 feeding

252 records covering 109 of southern Africa's 168 species, collected over a period of more than 130

253 years (Fig. 2). Contrastingly, in five years, we were able to collect 1066 feeding records, which

254 equates to $27.0 \%$ of all documented observations. When unsubstantiated records are included, as

255 a conservative measure, our observations from Facebook account for $24.3 \%$ of all feeding

256 records.

257

258 Overall, feeding observations accrued at a significantly faster rate (Welch's t-test: $\mathrm{t}=-3.94, \mathrm{p}=$ $2590.0163)$ by utilising Facebook $\left(\mu=213\right.$ records $\left.\cdot \mathrm{yr}^{-1}\right)$ compared to historical collection and 260 reporting approaches $\left(\mu=20.9\right.$ records $\left.\cdot \mathrm{yr}^{-1}\right)$. To account for gaps in reporting, we conducted a 261 moving average analysis to test if there were any time periods that produced comparable rates of 262 data accumulation. There were no five-year periods that approached or exceeded the 263 accumulation rate observed using Facebook. The most comparable period was between 2006$2642010\left(\mu=139\right.$ records $\left.\cdot \mathrm{yr}^{-1}\right)$ which produced 696 records. Only after expanding the time frame to 265 a 10-year window did the number of accumulated records from the literature $(\mathrm{N}=1187)$ exceed 266 the number of records that were collected using Facebook in half of the time. This period of high 267 reporting rate can be attributed to the publication of several multi-taxa museum studies from 268 1998-2007 (Shine et al., 1998; Keogh et al., 2000; Webb et al., 2000; Webb et al., 2001; Shine et 269 al., 2006a; Shine et al., 2006b; Shine et al., 2007). Importantly, the periods of comparable 270 reporting rates are the result of decades of work that ultimately culminated in the publication of 271 the literature during those periods, rather than actual rates of record accrual as represented by our 272 Facebook dataset.

273 
274 We found important differences in the taxonomic resolution to which prey species were

275 identified when comparing the two datasets. Prey were identified to the species level in $76.6 \%$ of

276 Facebook records compared to only $50.4 \%$ of literature records $\left(X^{2}=216.9, \mathrm{p}<0.0001\right)$ (Fig.

277 3) - probably because digestion of prey items in the gut of museum specimens often eliminates

278 diagnostic characteristics. Similarly, a significantly larger proportion of the Facebook records

279 were identifiable to at least the level of genus, family, and order than records in the literature

280 dataset $\left(X^{2}=49.13-250.6\right.$, all $\left.\mathrm{p}<0.0001\right)$.

281

282 Broadly speaking, the number of feeding observations for each snake species was moderately

283 correlated across the two approaches (Spearman's correlation: $\rho=0.490, \mathrm{p}<0.0001$ ). However,

284 this relationship obscures some dramatic differences in the overlap in trophic interactions

285 detected via each approach. For interactions with species-level identification of prey items, we

286 identified 441 and 781 distinct interactions within the Facebook and literature datasets,

287 respectively (Fig. 4). Surprisingly, only 114 of these interactions were shared between the two

288 datasets, and, notably, 327 interactions (of the 441 interactions detected; $74.1 \%$ ) were unique to

289 the Facebook dataset. Cohen's kappa coefficient $(\kappa=-0.652)$ confirmed that the approaches were

290 highly discordant in a non-random manner. Given the bias toward higher-level taxonomic

291 resolution for prey in the literature dataset (Fig. 3), we recalculated Cohen's kappa coefficient

292 with interactions aggregated at the level of genus, family, and order and found low concordance

293 across all taxonomic levels of prey identification $(\kappa=-0.652--0.289)$ with order-level

294 taxonomic assignment showing the greatest, but still poor, level of concordance. Depending on

295 level of prey identification (i.e. taxonomic aggregation), our analyses revealed that $28.4-74.1 \%$

296 of the interactions detected via Facebook were previously undocumented (Fig. 4). Remarkably, 
297 even at the coarse taxonomic aggregation level of order, $28.4 \%$ of interactions detected using

298 Facebook were novel.

299

300 On iNaturalist, we found 102 snake feeding observations by querying the database. The earliest 301 upload date of a feeding observations was in 2011 with an average of 11.3 observations added 302 per year since then - a rate that is significantly slower (Welch's t-test: $t=4.15, p=0.0139$ ) than 303 Facebook $\left(\mu=213\right.$ records $\left.\cdot \mathrm{yr}^{-1}\right)$. The greatest number of feeding observations reported on 304 iNaturalist occurred in $2019(\mathrm{~N}=39)$ and represents fewer observations than the number of 305 uploads to our Facebook group during its first year $(\mathrm{N}=54)$. Eight of the top-ten snake species 306 recorded in the iNaturalist dataset were also in the top-ten in the Facebook dataset. Notably, the 307 brown house snake (Boaedon capensis) had the most observations on both platforms.

308 Interestingly, of the 57 distinct interactions with prey identified to the species-level that were 309 reported on iNaturalist, 19 species interactions were not detected using Facebook and 13 310 interactions were not present in either the Facebook or the literature dataset.

312 We gathered an additional seven feeding observations for four target species (B. capensis, 313 Python natalensis, Dispholidus typus, and Naja nivea) by visually searching through species 314 records for uncatalogued records. Across all four target species, Facebook outperformed 315 iNaturalist (Fig. 5A). However, the number of records obtained for each of the target species was 316 proportionally similar between the two platforms. The maximum difference in proportions 317 equated to $3.68 \%$ (D. typus, Facebook: 7.32\% vs. iNaturalist: $11.0 \%$ ). Finally, at least 9.2\% of all 318 iNaturalist records were duplicates of records found using Facebook (i.e., exact photo). 
320 Targeted Google Images searches for the four target species returned 13-25 records per species

$321(\mathrm{~N}=72)$ which exceeds the number of records posted to iNaturalist for each target species but

322 still underperformed relative to Facebook (Fig. 5A). 19.4\% of records were duplicates of feeding

323 events found using Facebook. Importantly, the ratio of prey types for several of the target species

324 were heavily skewed depending on the source of the observation (Fig. 5B-5E). In particular,

$32584.2 \%$ of records for $N$. nivea depicted ophiophagy (i.e., snake-eating), particularly involving

326 puff adders (Bitis arietans) and mole snakes (Pseudaspis cana) (Fig. 5E). Additionally, 84.6\% of

327 P. natalensis observations involved animals feeding on large mammals (e.g., antelope) and our

328 search failed to produce any instances of bird-eating (Fig. 5C). Remarkably, this method did not

329 produce any novel species interactions.

330

331 Discussion

332 Our study demonstrates the utilisation of Facebook as a crowdsourcing tool to gather a

333 geographically and taxonomically diverse dataset of difficult to observe trophic interactions

334 involving southern African herpetofauna as predators and as prey. Despite these types of

335 interactions being difficult to observe, our approach has yielded observations faster, at finer

336 taxonomic resolution, and that differ significantly from what is currently known within 138 years

337 of herpetological literature. Taken together, these findings provide a powerful example of the

338 potential application of social media to gather discrete, ephemeral ecological interactions.

339

340 Importantly, our work is part of a growing recognition of the remarkable power of social media

341 and citizen science to gather biological information (reviewed by Toivonen et al., 2019 and Jaríc

342 et al., 2020). Although a number of studies have made use of digital media platforms (i.e., not 
343 specifically designed for citizen science) to better understand the geographic and temporal

344 distribution of biological traits or organisms (Leighton et al., 2016; Jimenez-Valverde et al.,

345 2019; Marshal \& Strine, 2019), other studies have started to detail ecological and evolutionary

346 processes explicitly. Google Images has been used to quantify insect-pollinator relationships

347 (Bahlai \& Landis, 2016), commensalism-like relationships between birds and large mammals

348 (Mikula et al., 2018), to assess the diets of predatory birds (Mikula et al., 2016; Naude et al.,

349 2019), and the diets of predatory insects (Hernandez et al., 2019). Similarly, Facebook has been

350 used to quantify co-grazing patterns between two deer species (Mori, Bari, \& Coraglia, 2018)

351 and ad hoc observations have revealed a fascinating foraging strategy in skunks (Pesendorfer,

352 Dickerson, \& Dragoo, 2018). Importantly, many of these taxa are often conspicuous due to their

353 size, colouration, microhabitat usage, or duration spent in one location, and the resources in

354 several of the studies are conspicuous (for the same reasons) or spatially restricted. Ultimately,

355 these characteristics improve detection probability and reporting rates. Conversely, our study has

356 demonstrated that social media (specifically Facebook) draws observational power from such a

357 large network that even elusive ecological interactions with low temporal and spatial

358 predictability can be gathered rapidly.

359

360 Our approach has several strengths that make its application in ecological and evolutionary

361 studies appealing. Firstly, the ease of reporting means that observers are more likely to share

362 their observations. A dedicated, actively managed, public group allows for photos to be funnelled

363 from across Facebook, and many of our observers had already shared their observations to

364 Facebook in some other context before those posts were shared to our dedicated predation

365 records group. Importantly, the group acts as an outlet for observations that would never 
366 otherwise have been documented formally; now, those records can be incorporated into a

367 growing database. Secondly, while citizen science projects like iNaturalist and iSpot attract many

368 users, citizen science platforms are mainly populated by a few very active users (Sauermann \&

369 Franzoni, 2015). Facebook does not require an inherent interest in a particular topic which allows

370 for a diverse range of media to be posted and shared publicly. Together with the low probability

371 of encountering feeding events - as indicated by the number of single observations in our

372 dataset - dedicated flora and fauna platforms do not attract enough observers to gather sizeable

373 datasets, especially outside of major populated areas. Thirdly, the interactive nature of Facebook

374 facilitates direct communication with observers which can result in more photos or details, if

375 needed. Information such as locality data can be requested directly from observers thus reducing

376 the reliance on geo-tagging functions of social media platforms, which can be incorrect or

377 missing from posts altogether (Di Minin, Tenkanen, \& Toivonen, 2015). Fourth, the Facebook

378 group format provides an ideal platform to discuss identification of species with interested

379 experts, thereby facilitating expert-crowdsourcing of species identifications. Austen et al. (2018)

380 proposed that the identification of species in digital natural history observations should be based

381 on more than one photo and verified by more than one expert. Thus, Facebook groups offer

382 effective mechanisms to meet these criteria. Finally, the community of observers receive

383 informed feedback from researchers regarding their observation. Unlike passive data collection

384 methods (i.e., media and data scraping), active engagement with observers and other members

385 acts as an opportunity to educate the public about the importance of an observation and active

386 engagement and feedback has the potential to incentivise continued participation. 
388 The data gathered via our approach is not without its context-specific challenges. Primarily, our 389 approach does not offer an obvious mechanism for quantifying sampling effort, prohibiting rate390 or density-dependent analyses of these processes. Secondly, our approach, as with nearly all 391 sampling approaches, may overrepresent certain interactions in important ways (Glaudas, 392 Kearney, \& Alexander, 2017). For one, our approach is likely to include events that happen (1) 393 frequently, (2) near humans (either urban areas or well-trafficked nature reserves), (3) near 394 humans with the means to access the internet (which shows socioeconomic and regional bias; 395 Kemp, 2020), and (4) over longer periods of time. Third, the permanence of posts and their 396 associated media, which appear on social media platforms like Facebook, are not guaranteed, and 397 images may be removed or their visibility settings may be changed by the owner at any time. As 398 a result, there is a need to store images and data outside of the platform in a timely manner. 399 Finally, we have adopted to manually curate and log observations into a database rather than 400 seek automated approaches in part due to the loss of API function in April 2018 associated with 401 a change in Facebook's terms of service (Freelon, 2018). This manual approach has worked well 402 at the scale of our analysis but will become problematic at the scale of some of the data that 403 social media has the potential to gather. Advances in machine learning for identification of 404 species in images are progressing rapidly (reviewed by Wäldchen \& Mäder, 2018) and are 405 starting to be utilised for scientific assessment of social media images (Di Minin et al., 2018). 406 However, in our context, we continue to be limited by the fact that the observations being 407 reported are inherently difficult to observe, thus limiting the availability of sufficient amounts of 408 training data. Nonetheless, automation of image identification, or even social media group 409 administration, will be required to scale our approach to truly global ecological or evolutionary 410 questions. 
412 The relatively low measures of concordance between the data gathered via Facebook, and that 413 reported in the literature (Fig. 4), or via other digital media platforms (Fig. 5B-5E) raises the 414 important question of which approach more closely reflects reality. Some approaches to studying 415 diet such as fixed videography (Glaudas et al., 2017) and DNA barcoding of prey remains 416 (reviewed by Alberdi et al., 2019) offer promising future prospects for relatively unbiased 417 dietary analysis for many organisms, including snakes. However, these approaches are incredibly 418 effort- and cost-intensive, limiting their widespread application. Currently, it is unclear to what 419 degree our data might bias for or against detection of certain interactions. However, we are 420 encouraged by the detection in our Facebook dataset of several apparently difficult to detect 421 interactions (e.g., puff adders (Bitis arietans) consuming amphibians, the first reported diet 422 record for Swazi rock snakes (Inyoka swazicus)), and interactions with incredibly short handling 423 times (e.g., a vine snake (Thelotornis capensis) catching and swallowing a rain frog (Breviceps 424 sp.) in under 20 seconds). It is apparent from our analysis that Google Images may be the least 425 effective means for collecting representative diet data, at least for our study system. This is likely 426 to be the case because not all webpages are indexed by Google, (including Facebook) and blogs 427 or media outlets are dominated by eye-catching photos and particularly notable or lengthy 428 encounters. On the other hand, iNaturalist may provide more representative data that can be used 429 in corroboration with Facebook data, which can be promising for geographic regions with more 430 involvement (e.g., United States of America: 483000+; United Kingdom: 28000+; South Africa: $4317300+$ observers). 
433 Our approach has several implications for our understanding of snake biology. It is well-

434 established that diet has played a major role in the evolution of snakes (Greene, 1983; Colston et

435 al., 2010) and their venoms (Daltry et al., 1996; Barlow et al., 2009; Casewell et al., 2013).

436 Additionally, snake feeding, either through demographic effects on prey populations, risk of

437 predation and 'landscape of fear' dynamics, or the selective agents for prey anti-predatory

438 adaptations, are likely to represent the major impacts that snakes have within ecosystems and

439 food webs. Understanding these processes is linked inextricably with high-quality natural history

440 data regarding variation in snake diets, leading to a recent attempt to centralise and analyse

441 feeding data at a global scale (Grundler, 2020). However, our understanding of the details of

442 snake diets remains surprisingly superficial, especially in places like Africa where snakebite is a

443 major health concern (Harrison et al., 2009; Chippaux, 2011; Murray, Martin, \& Iwamura,

444 2020). In this context, we think that our novel approach to gathering natural history data can

445 provide a powerful tool to supplement existing datasets and, ultimately, improve our

446 understanding of snake feeding, thereby contextualising studies of snakes, their ecological

447 functions, and their venoms.

448

449 Our approach has enormous potential beyond our usage of it, and we look forward to seeing its

450 application in multiple ecological and evolutionary contexts. Even within our own dataset, we

451 have only begun to explore the full potential of our data by addressing species-specific questions

452 (Layloo, Smith, \& Maritz, 2017; Maritz, Alexander, \& Maritz, 2019; Maritz et al., 2019; Smith

453 et al., 2019). However, the dataset lends itself to addressing other questions such as seasonality

454 in feeding and prey preference, intraguild predation, and the evolution of diet. Additionally, we

455 see its value in documenting other ephemeral, discrete, event-driven processes similar to 
456 predation, particularly if they can be captured as photographs of the types of subjects already

457 shared to social media. For example, photographs of pollinators visiting flowers could be crowd-

458 sourced and curated to better understand pollination dynamics, images of identifiable individual

459 animals (e.g., distinct markings) could be used to assess seasonal body condition, home range

460 size, and lifespan, and photographs of urban biodiversity could elucidate novel urban ecology

461 interactions between species, or even human-wildlife conflict. Importantly, images of many of

462 these types of events are being shared on social media platforms already, and all that is required

463 is for interested researchers to start engaging with those data.

464

465 Conclusions

466 Employing social media as a citizen science platform allowed for the collection of trophic data 467 across a remarkable diversity of interactions involving African reptiles and amphibians.

468 Particularly, the results of the dietary analysis of snakes demonstrate how rapidly and precisely

469 information can be collected to characterise an ecological process compared to traditional

470 approaches. Additionally, the results show a large discordance between sampling via social

471 media and traditional approaches including the detection of many novel interactions, which

472 emphasises how undersampling can lead to gaps in our understanding. Finally, the results

473 highlight how social media can outperform traditional citizen science and crowdsourcing

474 approaches when observations involve elusive animals or unpredictable events, which is likely

475 due differences in the number of active members and thus overall sampling intensity. Beyond

476 herpetological studies, the observational power and approach showcased here has enormous

477 potential for the documentation and investigation of other rare events that underlie important 
478 ecological processes, and we emphasise that such approaches should no longer be considered 479 ancillary.

480

481 Acknowledgements

482 We acknowledge Andre Coetzer, Tyrone Ping, and Luke Verburgt for their roles in conceiving 483 the idea for the Predation Records - Reptiles and Frogs (Sub-Saharan Africa) Facebook group. 484 Additionally, we thank them and Gary Nicolau for assisting in the management of the group's 485 membership and discussions as admins. We are indebted to the members of the group (and other 486 members of the Facebook community) who have shared observations to and participated in our 487 research project. We thank the Facebook users who continue to encourage members on other 488 groups and pages to share their observations with us. For this, we acknowledge Norman Barrett, 489 Gary Brown, Ashley Kemp, Luke Kemp, Andrea Myburgh, and Francois Theart. We are grateful 490 for identifications provided by experts in the community. Particularly, we thank Werner 491 Conradie, James Harvey, Luke Kemp, Johan Marais, Gary Nicolau, Dan Parker, Tyrone Ping, 492 Dominic Rollinson, Stephen Spawls, and Luke Verburgt for their continued input. We recognise 493 the 2017 University of the Western Cape Biodiversity and Conservation Biology Herpetology 494 honours students for assisting in the early phase of the literature search. 


\section{References}

496 Alberdi, A, Aizpurua, O, Bohmann, K, Gopalakrishnan, S, Lynggaard, C, Nielsen, M, Gilbert,

497

498

499

500

501

502

503

504

505

506

507

508

509

510

511

512

513

514

515

516

517 Colston, TJ, Costa, GC, Vitt, LJ. 2010. Snake diets and the deep history hypothesis. Biological MT. 2019. Promises and pitfalls of using high-throughput sequencing for diet analysis. Molecular Ecology Resources 19:327-348 DOI: 10.1111/1755-0998.12960

Austen, GE, Bindemann, M, Griffiths, RA, Roberts, DL. 2018. Species identification by conservation practitioners using online images: Accuracy and agreement between experts. PeerJ, 6:e4157 DOI: 10.7717/peerj.4157

Bahlai, CA, Landis, DA. 2016. Predicting plant attractiveness to pollinators with passive crowdsourcing. Royal Society Open Science 3:150677 DOI: 10.1098/rsos.150677

Barlow, A, Pook, CE, Harrison, RA, Wüster, W. 2009. Coevolution of diet and prey-specific venom activity supports the role of selection in snake venom evolution. Proceedings of the Royal Society B: Biological Sciences 276:2443-2449 DOI: 10.1098/rspb.2009.0048

Casewell, NR, Wüster, W, Vonk, FJ, Harrison, RA, Fry, BG. 2013. Complex cocktails: the evolutionary novelty of venoms. Trends in Ecology \& Evolution 28:219-229 DOI: 10.1016/j.tree.2012.10.020

Chacoff, NP, Vázquez, DP, Lomáscolo, SB, Stevani, EL, Dorado, J, Padrón, B. 2011. Evaluating sampling completeness in a desert plant-pollinator network. Journal of Animal Ecology 81:190-200 DOI: 10.1111/j.1365-2656.2011.01883.x

Chippaux, J. 2011. Estimate of the burden of snakebites in sub-Saharan Africa: a meta-analytic approach. Toxicon 57:586-599 DOI: 10.1016/j.toxicon.2010.12.022

Cohen, J. 1960. A coefficient of agreement for nominal scales. Educational and Psychological Measurement 20:37-46 DOI: 10.1177/001316446002000104 
519 Daltry, JC, Wüster, W, Thorpe, RS. 1996. Diet and snake venom evolution. Nature 379:537-554

520 DOI: $10.1038 / 379537 \mathrm{a} 0$

521 Di Minin, E, Fink, C, Tenkanen, H, Hiippala, T. 2018. Machine learning for tracking illegal 522 wildlife trade on social media. Nature Ecology \& Evolution 2:406-407 DOI:

523 10.1038/s41559-018-0466-X

524

525

526

527

528

529

530

531

532

533

534

535

536

537

538

539

540

Di Minin, E, Tenkanen, H, Toivonen, T. 2015. Prospects and challenges for social media data in conservation science. Frontiers in Environmental Science 3:63 DOI: $10.3389 /$ fenvs.2015.00063

Durso, AM, Willson, JD, Winne, CT. 2011. Needles in haystacks: Estimating detection probability and occupancy of rare and cryptic snakes. Biological Conservation 144:15081515 DOI: 10.1016/j.biocon.2011.01.020

Durso, AM, Seigel, RA. 2015. A snake in the hand is worth 10,000 in the bush. Journal of Herpetology 49:503-506 DOI: 10.1670/15-49-04.1

Facebook. 2019, October 30. Facebook Reports Third Quarter 2019 Results [Press Release]. Available at https://investor.fb.com/investor-news/press-release-details/2019/FacebookReports-Third-Quarter-2019-Results/default.aspx (accessed 20 January 2020)

FitzSimons, VFM. 1962. Snakes of Southern Africa. Cape Town, South Africa: Purnell and Sons. Freelon, D. 2018. Computational research in the post-API age. Political Communication 35:665668 DOI: $10.1080 / 10584609.2018 .1477506$

Garvey, JE, Whiles, M. 2017. Trophic Ecology. London, England: CRC Press.

Glaudas, X, Kearney, TC, Alexander, GJ. 2017. Museum specimens bias measures of snake diet: a case study using the ambush-foraging puff adder (Bitis arietans). Herpetologica 73:121- 
542 Greene, HW. 1983. Dietary correlates of the origin and radiation of snakes. American Zoologist

543 23:431-441 DOI: 10.1093/icb/23.2.431

544 Greene, HW, Jaksić, FM. 1983. Food-niche relationships among sympatric predators: effects of 545 level of prey identification. Oikos 40:151-154 DOI: $10.2307 / 3544212$

546 Greene, HW. 1997. Snakes: The Evolution of Mystery in Nature. Berkeley, California:

$547 \quad$ University of California Press.

548 Grundler, MC. 2020. SquamataBase: a natural history database and R package for comparative 549 biology of snake feeding habits. Biodiversity Data Journal 8:e49943 DOI:

550 10.3897/BDJ.8.e49943

551

552

553

554

555

556

557

558

559

560

561

562

563

Harrison, RA, Hargreaves, A, Wagstaff, SC, Faragher, B, Lalloo, DG. 2009. Snake envenoming: a disease of poverty. PLoS Neglected Tropical Diseases 3:e569 DOI:

$$
\text { 10.1371/journal.pntd.0000569 }
$$

Hegland, SJ, Dunne, J, Nielsen, A, Memmott, J. 2010. How to monitor ecological communities cost-efficiently: the example of plant-pollinator networks. Biological Conservation 143:2092-2101 DOI: 10.1016/j.biocon.2010.05.018

Hernandez, M, Masonick, P, Weirauch, C. 2019. Crowdsourced online images provide insights into predator-prey interactions of putative natural enemies. Food Webs 21:e00126 DOI: 10.1016/j.fooweb.2019.e00126

Iverson, JB. 1982. Biomass in turtle populations: a neglected subject. Oecologia 55:69-76 DOI: $10.1007 / \mathrm{bf00386720}$

Jacobsen, NHG. 1982. The ecology of the reptiles and amphibians in the Burkea africanaEragrostis pallens savanna of the Nylsvley Nature Reserve. M. Sci. Thesis, University of 
564 Pretoria, South Africa.

565 Jarić, I, Correia, RA, Brook, BW, Buettel, JC, Courchamp, F, Di Minin, E, Firth, JA, Gaston, KJ,

566 Jepson, P, Kalinkat, G, Ladle, R, Soriano-Redondo, A, Souza, AT, Roll, U. 2020.

567 iEcology: harnessing large online resources to generate ecological insights Trends in

568 Ecology and Evolution [In Press] DOI: 10.1016/j.tree.2020.03.003

569 Jiménez-Valverde, A, Peña-Aguilera, P, Barve, V, Burguillo-Madrid, L. 2019. Photo-sharing

570 platforms key for characterising niche and distribution in poorly studied taxa. Insect

571 Conservation and Diversity 12: 389-403 DOI: 10.1111/icad.12351

572 Jordano, P. 2016. Sampling networks of ecological interactions. Functional Ecology 30:1883-

$573 \quad 1893$ DOI: $10.1101 / 025734$

574 Kemp, S. 2020, January 30. Digital 2020: 3.8 Billion People Use Social Media. Available at 575 https://wearesocial.com/blog/2020/01/digital-2020-3-8-billion-people-use-social-media $576 \quad$ (accessed 10 May 2020)

577 Keogh, J, Branch, WR, Shine, R. 2000. Feeding ecology, reproduction and sexual dimorphism in 578 the colubrid snake Crotaphopeltis hotamboeia in southern Africa. African Journal of 579 Herpetology 49:129-137 DOI: 10.1080/21564574.2000.9635439

580 Lardner, B, Rodda, GH, Adams, AA, Savidge, JA, Reed, RN. 2015. Detection rates of geckos in $581 \quad$ visual surveys: turning confounding variables into useful knowledge. Journal of 582 Herpetology 49: 522-532 DOI: 10.1670/14-048

583 Layloo, I, Smith, C, Maritz, B. 2017. Diet and feeding in the cape cobra, Naja nivea. African 584 Journal of Herpetology 66:147-153 DOI: 10.1080/21564574.2017.1388297

585 Leighton, GR, Hugo, PS, Roulin, A, Amar, A. 2016. Just Google it: assessing the use of Google 586 Images to describe geographical variation in visible traits of organisms. Methods in 
588

589

590

591

592

593

594

595

596

597

598

599

600

601

602

603

604

605

606

607

608

609

Maritz, B, Alexander, GJ, Maritz, RA. 2019. The underappreciated extent of cannibalism and ophiophagy in African cobras. Ecology 100:e02522 DOI: 10.1002/ecy.2522

Maritz, R, Conradie, W, Sardinha, CI, Peto, A, Chechene, AHC, Maritz, B. 2019. Ophiophagy and cannibalism in African vine snakes (Colubridae: Thelotornis). African Journal of Ecology [early view] DOI: 10.1111/aje.12702

Marshall, BM, Strine, CT. 2019. Exploring snake occurrence records: spatial biases and marginal gains from accessible social media. PeerJ 7:e8059 DOI: 10.7717/peerj.8059

McCann, K. 2007. Protecting biostructure. Nature 446:29 DOI: 10.1038/446029a

Mikula, P, Morelli, F, Lučan, RK, Jones, DN, Tryjanowski, P. 2016. Bats as prey of diurnal birds: a global perspective. Mammal Review 46:160-174 DOI: 10.1111/mam.12060

Mikula, P, Hadrava, J, Albrecht, T, Tryjanowski, P. 2018. Large-scale assessment of commensalistic--mutualistic associations between African birds and herbivorous mammals using internet photos. PeerJ 6:e4520 DOI: 10.7717/peerj.4520

Miranda, M, Parrini, F, Dalerum, F. 2013. A categorization of recent network approaches to analyse trophic interactions. Methods in Ecology and Evolution 4:897-905 DOI: 10.1111/2041-210x.12092

Mori, E, Bari, PD, Coraglia, M. 2018. Interference between roe deer and Northern chamois in the Italian Alps: are Facebook groups effective data sources? Ethology Ecology \& Evolution 30:277-284 DOI: 10.1080/03949370.2017.1354922

Murray, KA, Martin, G, Iwamura, T. 2020. Focus on snake ecology to fight snakebite. Lancet 395:e14 DOI: 10.1016/S0140-6736(19)32510-3

Naude, VN, Smyth, LK, Weideman, EA, Krochuk, BA, Amar, A. 2019. Using web-sourced 
610 photography to explore the diet of a declining African raptor, the Martial Eagle

611 (Polemaetus bellicosus). Condor 121:1-9 DOI: 10.1093/condor/duy015

612 Paine, RT. 1988. Road maps of interactions or grist for theoretical development? Ecology

613 69:1648-1654 DOI: $10.2307 / 1941141$

614 Pesendorfer, MB, Dickerson, S, Dragoo, JW. 2018. Observation of tool use in striped skunks:

615 how community science and social media help document rare natural phenomena.

$616 \quad$ Ecosphere 9:e02484 DOI: 10.1002/ecs2.2484

617 Petranka, JW, Murray, SS. 2001. Effectiveness of removal sampling for determining salamander 618 density and biomass: a case study in an Appalachian streamside community. Journal of 619 Herpetology 35:36-44 DOI: 10.2307/1566020

620 Pincheira-Donoso, D, Bauer, AM, Meiri, S, Uetz, P. 2013. Global taxonomic diversity of living 621 reptiles. PLoS One 8:e59741 DOI: 10.1371/journal.pone.0059741

622 Polis, GA. 1991. Complex trophic interactions in deserts: an empirical critique of food-web 623 theory. American Naturalist 138:123-155 DOI: $10.1086 / 285208$

624 Rodda, GH, Dean-Bradley, K, Campbell, EW, Fritts, TH, Lardner, B, Adams, AA, Reed, RN.

625 2015. Stability of detectability over 17 years at a single site and other lizard detection 626 comparisons from Guam. Journal of Herpetology 49:513-521 DOI: 10.1670/14-085

627 Sauermann, H, Franzoni, C. 2015. Crowd science user contribution patterns and their 628 implications. Proceedings of the National Academy of Sciences 112:679-684 DOI:

629 $10.1073 /$ pnas. 1408907112

630 Shine, R, Branch, WR, Webb, JK, Harlow, PS, Shine, T, Keogh, JS. 2007. Ecology of cobras 631 from southern Africa. Journal of Zoology 272:183-193 DOI: 10.1111/j.1469$632 \quad 7998.2006 .00252 . x$ 
633 Shine, R, Branch, WR, Harlow, PS, Webb, JK. 1998. Reproductive biology and food habits of

634 horned adders, Bitis caudalis (Viperidae), from southern Africa. Copeia 1998(2):391-401

635 DOI: $10.2307 / 1447433$

636 Shine, R, Branch, WR, Harlow, PS, Webb, JK, Shine, T. 2006a. Biology of burrowing asps

637 (Atractaspididae) from southern Africa. Copeia 2006(1):103-115 DOI: 10.1643/0045-

$638 \quad 8511(2006) 006[0103:$ bobaaf $] 2.0 . c 0 ; 2$

639 Shine, R, Branch, WR, Webb, JK, Harlow, PS, Shine, T. 2006b. Sexual dimorphism,

640 reproductive biology, and dietary habits of psammophiine snakes (Colubridae) from

641 southern Africa. Copeia 2006(4):650-664 DOI: 10.1643/0045-

$642 \quad 8511(2006) 6[650: \operatorname{sdrbad}] 2.0 . \operatorname{co} ; 2$

643 Smith, CCD, Layloo, I, Maritz, RA, Maritz, B. 2019. Sexual dichromatism does not translate

644 into sex-based difference in morphology or diet for the African boomslang. Journal of

645 Zoology 308:253-258 DOI: $10.1111 /$ jzo.12670

646 Steen, DA. 2010. Snakes in the grass: secretive natural histories defy both conventional and

647 progressive statistics. Herpetological Conservation and Biology 5:183-188.

648 Thompson, RM, Townsend, CR. 2000. Is resolution the solution?: The effect of taxonomic

649 resolution on the calculated properties of three stream food webs. Freshwater Biology

650 44:413-422 DOI: 10.1046/j.1365-2427.2000.00579.x

651 Toivonen, T, Heikinheimo, V, Fink, C, Hausmann, A, Hiippala, T, Järv, O, Tenkanen, H, Di

652 Minin, E. 2019. Social media data for conservation science: a methodological overview.

653 Biological Conservation 233:298-315 DOI: 10.1016/j.biocon.2019.01.023

654 Tylianakis, JM, Didham, RK, Bascompte, J, Wardle, DA. 2008. Global change and species

655 interactions in terrestrial ecosystems. Ecology Letters 11:1351-1363 DOI: 10.1111/j.1461- 
657 Valiente-Banuet, A, Aizen, MA, Alcántara, JM, Arroyo, J, Cocucci, A, Galetti, M, García, MB, 658 García, D, Gómez, JM, Jordano, P, Medel, R, Navarro, L, Obeso, JR, Oviedo, R, Ramírez, 659 N, Rey, PJ, Traveset, A, Verdú, M, Zamora, R. 2014. Beyond species loss: the extinction 660 of ecological interactions in a changing world. Functional Ecology 29:299-307 DOI:

$661 \quad 10.1111 / 1365-2435.12356$

662 Vitousek, PM, Mooney, HA, Lubchenco, J, Melillo, JM. 1997. Human domination of Earth's 663 ecosystems. Science 277:494-499 DOI: 10.1126/science.277.5325.494

664 Webb, JK, Branch, WR, Shine, R. 2001. Dietary habits and reproductive biology of typhlopid 665 snakes from southern Africa. Journal of Herpetology 35:558-567 DOI: 10.2307/1565893

666 Webb, JK, Shine, R, Branch, WR, Harlow, PS. 2000. Life-history strategies in basal snakes: 667 reproduction and dietary habits of the African thread snake Leptotyphlops scutifrons (Serpentes: Leptotyphlopidae). Journal of Zoology 250:321-327 DOI: 10.1111/j.1469-

669 7998.2000.tb00776.x

670 Western, D. 1974. The distribution, density and biomass density of lizards in a semi-arid 671 environment of northern Kenya. African Journal of Ecology 12:49-62 DOI:

672 10.1111/j.1365-2028.1974.tb00106.x

673 Wäldchen, J, Mäder, P. 2018. Machine learning for image based species identification. Methods 674 in Ecology and Evolution 9:2216-2225 DOI: 10.1111/2041-210x.13075

675 


\section{Figure Legends}

677 Figure 1: Diversity of predator-prey interactions detected using Facebook. (A) Number of

678 reptile and amphibian feeding records grouped by prey class. Each square represents 10 records.

679 Prey classes with $<10$ records are included within 'Other' (Arachnida, Chilopoda, Clitellata, 680 Diplopoda, Liliopsida, Magnoliopsida, and Malacostraca). (B-F) Examples of in situ feeding 681 interactions with reptiles and amphibians as predators collected from Facebook. (B) Cape cobra

682 (Naja nivea)-Tubercled gecko (Chondrodactylus sp.) Photo credit: Michele-Ann Nel. (C) Brown 683 house snake (Boaedon capensis)-African yellow bat (Scotophilus dinganii) Photo credit: Nick 684 van de Wiel. (D) Cape river frog (Amietia fuscigula)-Cape white-eye (Zosterops virens) Photo 685 credit: Basil Boer. (E) Waterberg flat lizard (Platysaurus minor)-African thief ant (Carebara 686 vidua) Photo credit: Kobus Pienaar. (F) Rhombic egg-eater (Dasypeltis scabra)-Indian peafowl 687 (Pavo cristatus) Photo credit: Sherry Woods. (G) Number of feeding records involving reptiles 688 or amphibians as prey grouped by predator class. Each square represents 10 records. Predator 689 classes with $<10$ records are included within 'Other' (Actinopterygii, Chilopoda, Insecta, and 690 Malacostraca). (H-L) Examples of in situ feeding interactions involving reptiles and amphibians 691 as prey collected from Facebook. (H) Many-horned adder (Bitis cornuta)-Spotted desert lizard 692 (Meroles suborbitalis) Photo credit: Jessica Kemper. (I) Jumping spider (Salticidae)-Cape dwarf 693 gecko (Lygodactylus capensis) Photo credit: Anton Roberts. (J) Brown water snake

694 (Lycodonomorphus rufulus)-Table Mountain ghost frog (Heleophryne purcelli) Photo credit:

695 Theo Busschau. (K) Rock kestrel (Falco rupicolus)- Bloubergstrand dwarf burrowing skink 696 (Scelotes montispectus) Photo credit: Paul Clinton. (L) Black-backed jackal (Canis mesomelas)697 Mole snake (Pseudaspis cana) Photo credit: Reg Lyons. 
699 Figure 2: Accumulation of snake feeding records from Facebook and literature sources.

700

701 Figure 3: Taxonomic resolution of snake prey items identified from Facebook and

702 literature sources. $* * *$ p-value $<0.0001$

703

704 Figure 4: Proportion of unique snake feeding interactions identified from Facebook and

705 literature sources. An interaction is defined as any instance of a specific snake species

706 consuming a specific prey item. Interactions were included only if the prey were identified to the

707 taxonomic level under analysis. Duplicate interactions within an approach were removed.

708

709 Figure 5: Comparison of feeding observations for four target snake species collected from

710 Facebook, iNaturalist, and Google Images. (A) The number of observations collected. (B-E)

711 The proportion of records with prey belonging to a given prey category. 


\section{Figure 1}

Diversity of predator-prey interactions detected using Facebook.

(A) Number of reptile and amphibian feeding records grouped by prey class. Each square represents 10 records. Prey classes with $<10$ records are included within 'Other' (Arachnida, Chilopoda, Clitellata, Diplopoda, Liliopsida, Magnoliopsida, and Malacostraca). (B-F) Examples of in situ feeding interactions with reptiles and amphibians as predators collected from Facebook. (B) Cape cobra (Naja nivea)-Tubercled gecko (Chondrodactylus sp.) Photo credit: Michele-Ann Nel. (C) Brown house snake (Boaedon capensis)-African yellow bat (Scotophilus dinganii) Photo credit: Nick van de Wiel. (D) Cape river frog (Amietia fuscigula)-Cape white-eye (Zosterops virens) Photo credit: Basil Boer. (E) Waterberg flat lizard (Platysaurus minor)-African thief ant (Carebara vidua) Photo credit: Kobus Pienaar. (F) Rhombic egg-eater (Dasypeltis scabra)-Indian peafowl (Pavo cristatus) Photo credit: Sherry Woods. (G) Number of feeding records involving reptiles or amphibians as prey grouped by predator class. Each square represents 10 records. Predator classes with $<10$ records are included within 'Other' (Actinopterygii, Chilopoda, Insecta, and Malacostraca). (H-L) Examples of in situ feeding interactions involving reptiles and amphibians as prey collected from Facebook. (H) Many-horned adder (Bitis cornuta)-Spotted desert lizard (Meroles suborbitalis) Photo credit: Jessica Kemper. (I) Jumping spider (Salticidae)-Cape dwarf gecko (Lygodactylus capensis) Photo credit: Anton Roberts. (J) Brown water snake (Lycodonomorphus rufulus)-Table Mountain ghost frog (Heleophryne purcelli) Photo credit: Theo Busschau. (K) Rock kestrel (Falco rupicolus)- Bloubergstrand dwarf burrowing skink (Scelotes montispectus) Photo credit: Paul Clinton. (L) Black-backed jackal (Canis mesomelas)-Mole snake (Pseudaspis cana) Photo credit: Reg Lyons. 

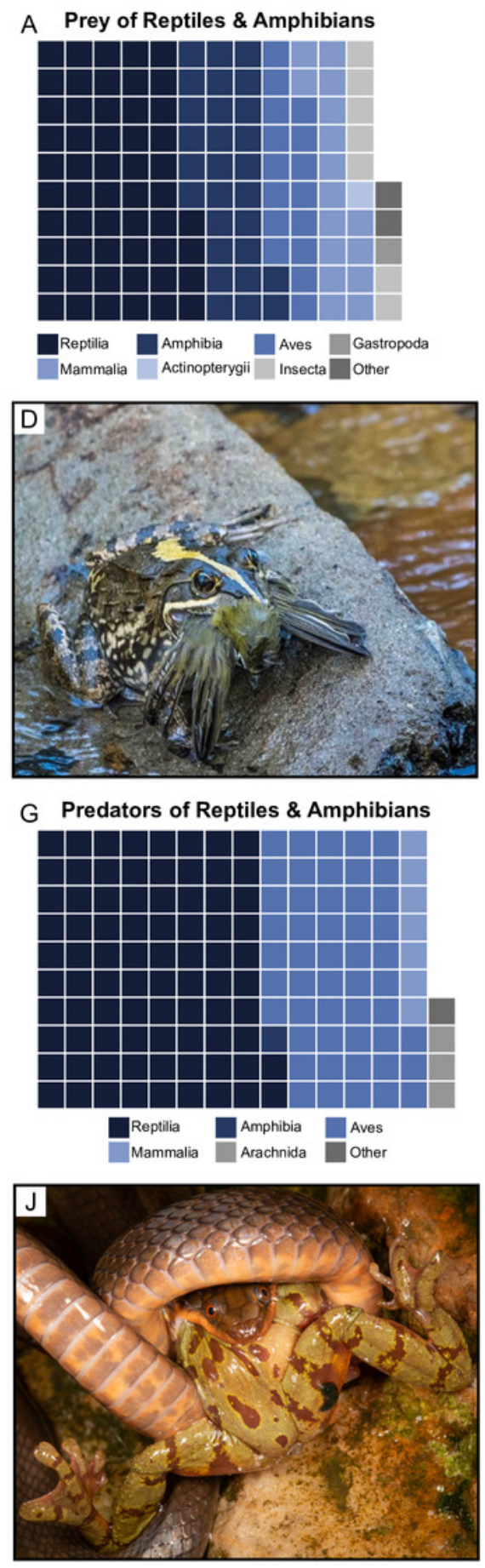
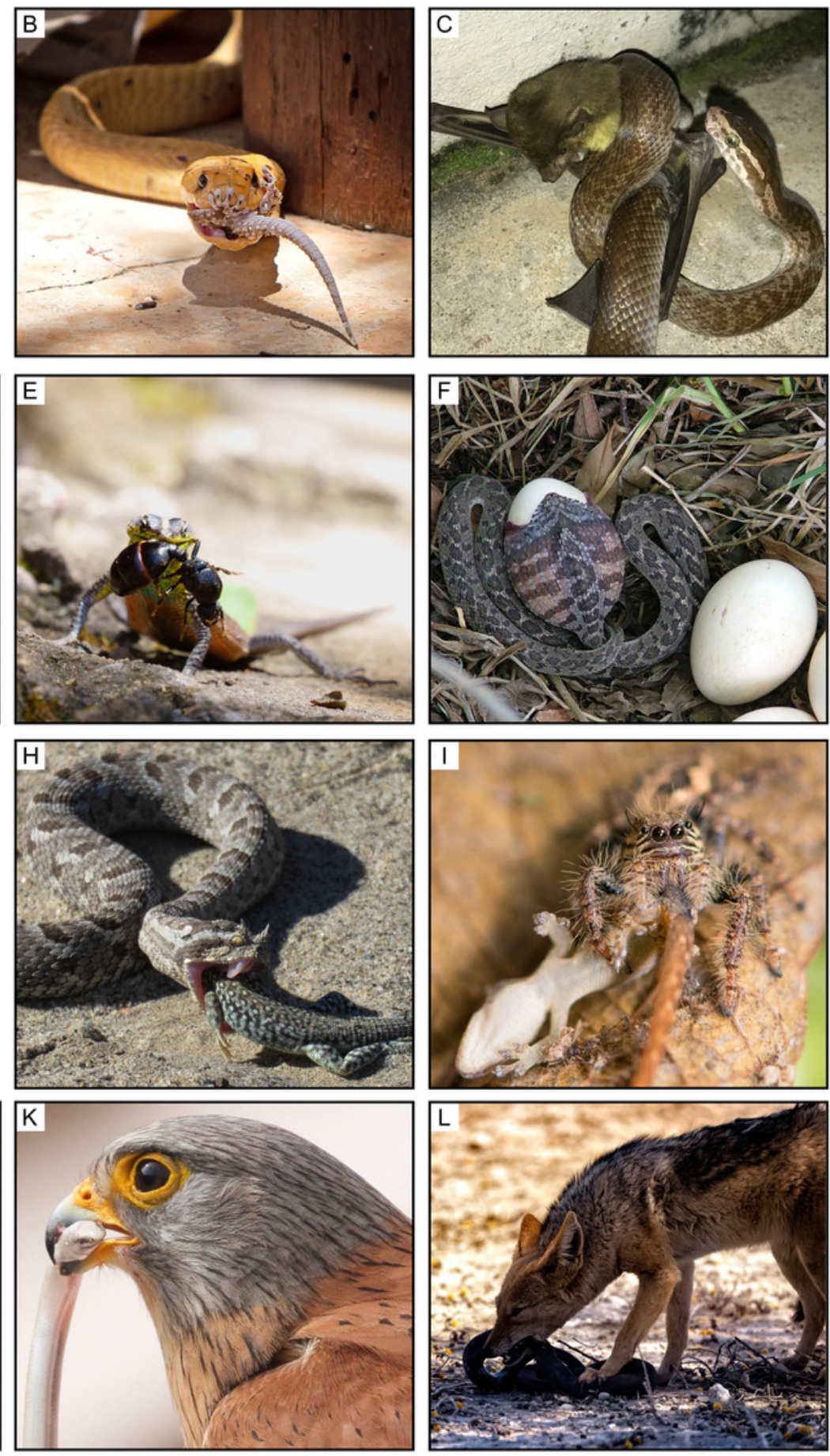
Figure 2

Accumulation of snake feeding records from Facebook and literature sources. 


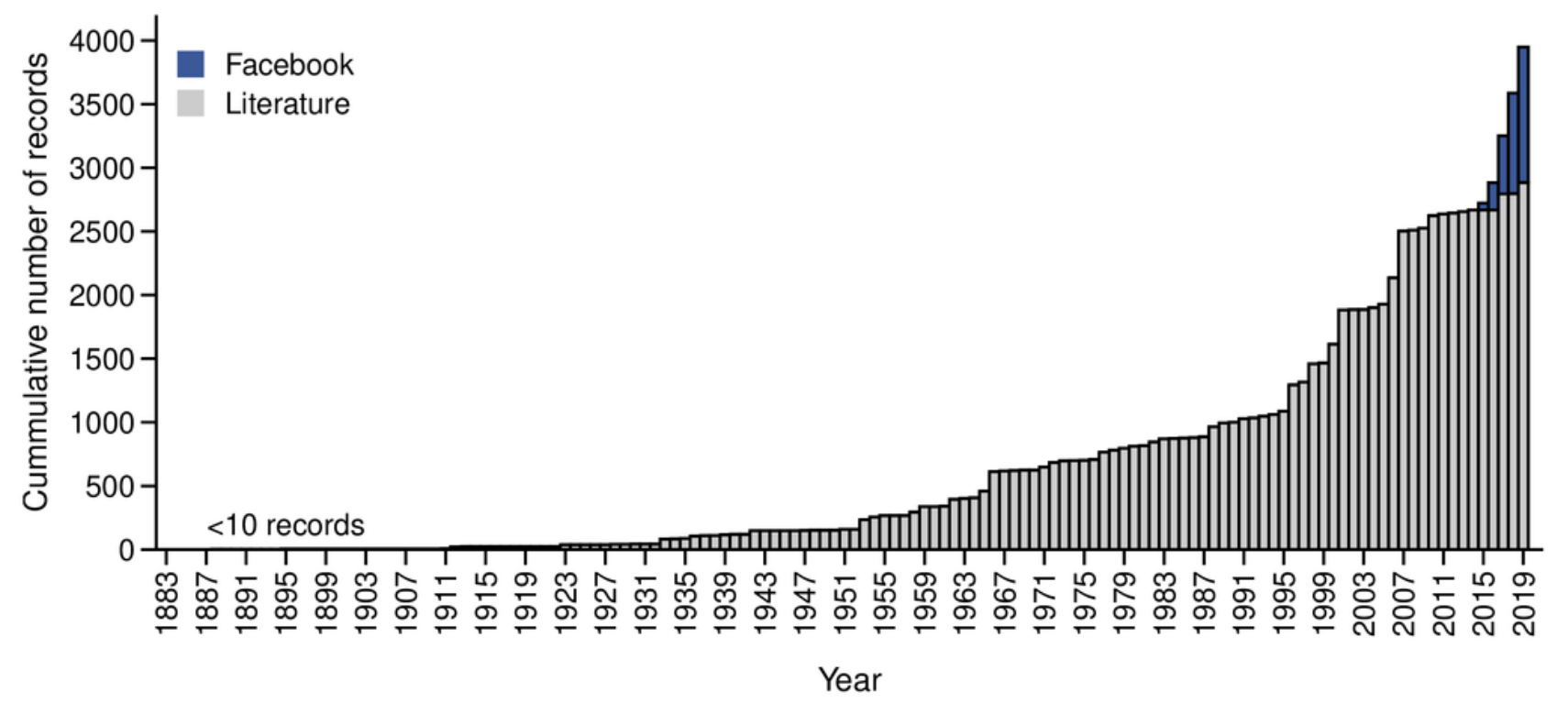


Figure 3

Taxonomic resolution of snake prey items identified from Facebook and literature sources.

$* * *$ p-value $<0.0001$ 


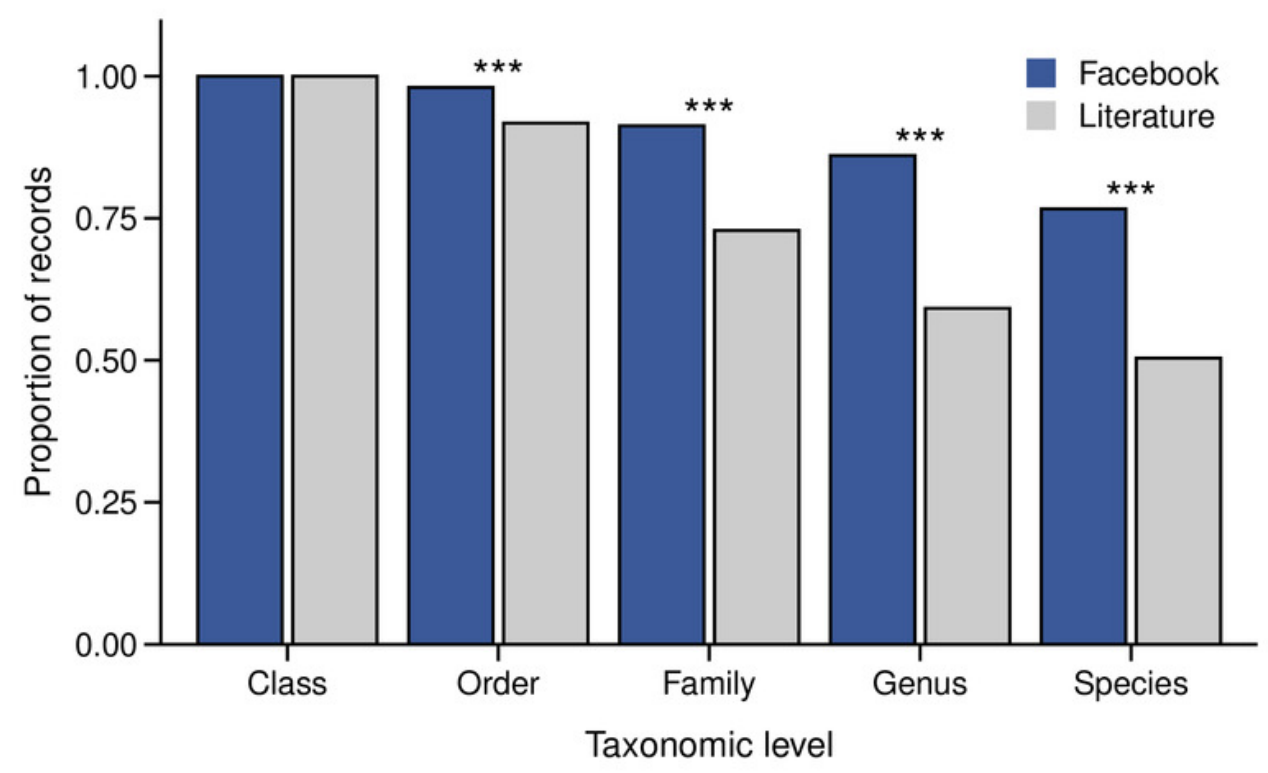




\section{Figure 4}

Proportion of unique snake feeding interactions identified from Facebook and literature sources.

An interaction is defined as any instance of a specific snake species consuming a specific prey item. Interactions were included only if the prey were identified to the taxonomic level under analysis. Duplicate interactions within an approach were removed. 


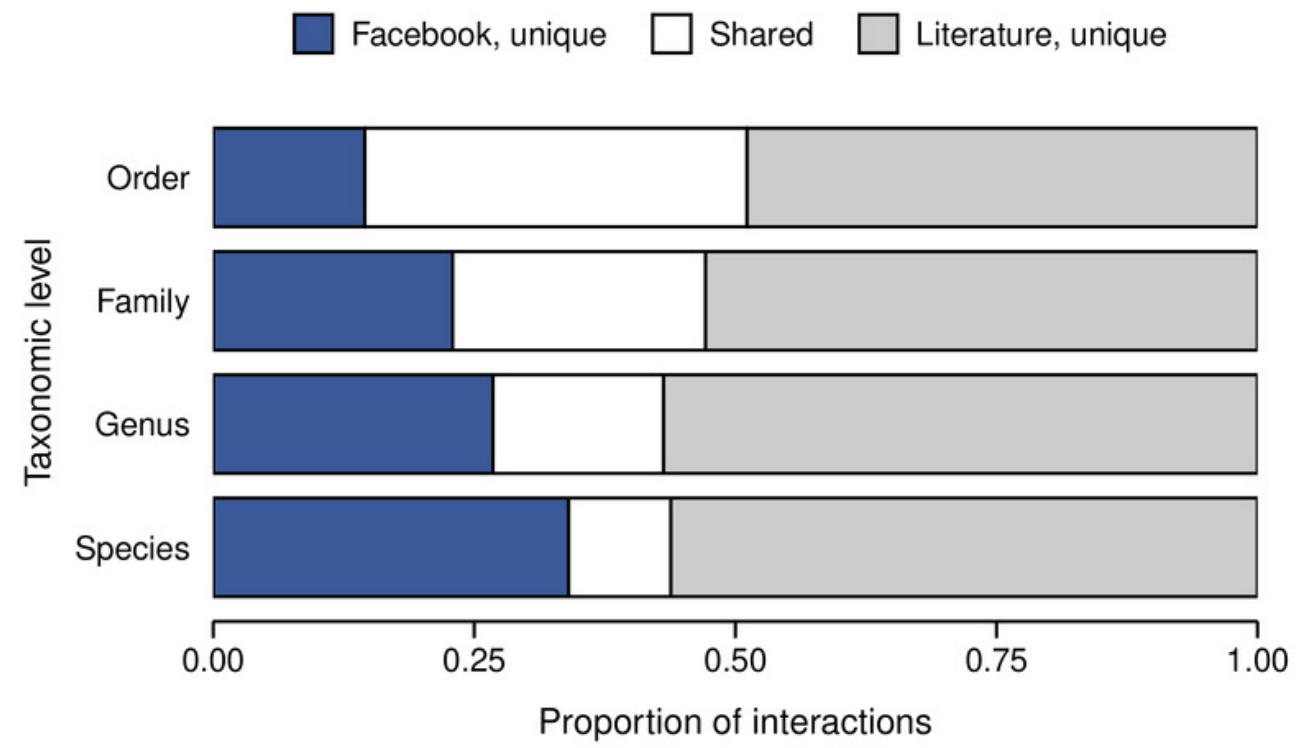


Figure 5

Comparison of feeding observations for four target snake species collected from Facebook, iNaturalist, and Google Images.

(A) The number of observations collected. (B-E) The proportion of records with prey belonging to a given prey category. 
A

Facebook iNaturalist Google Images
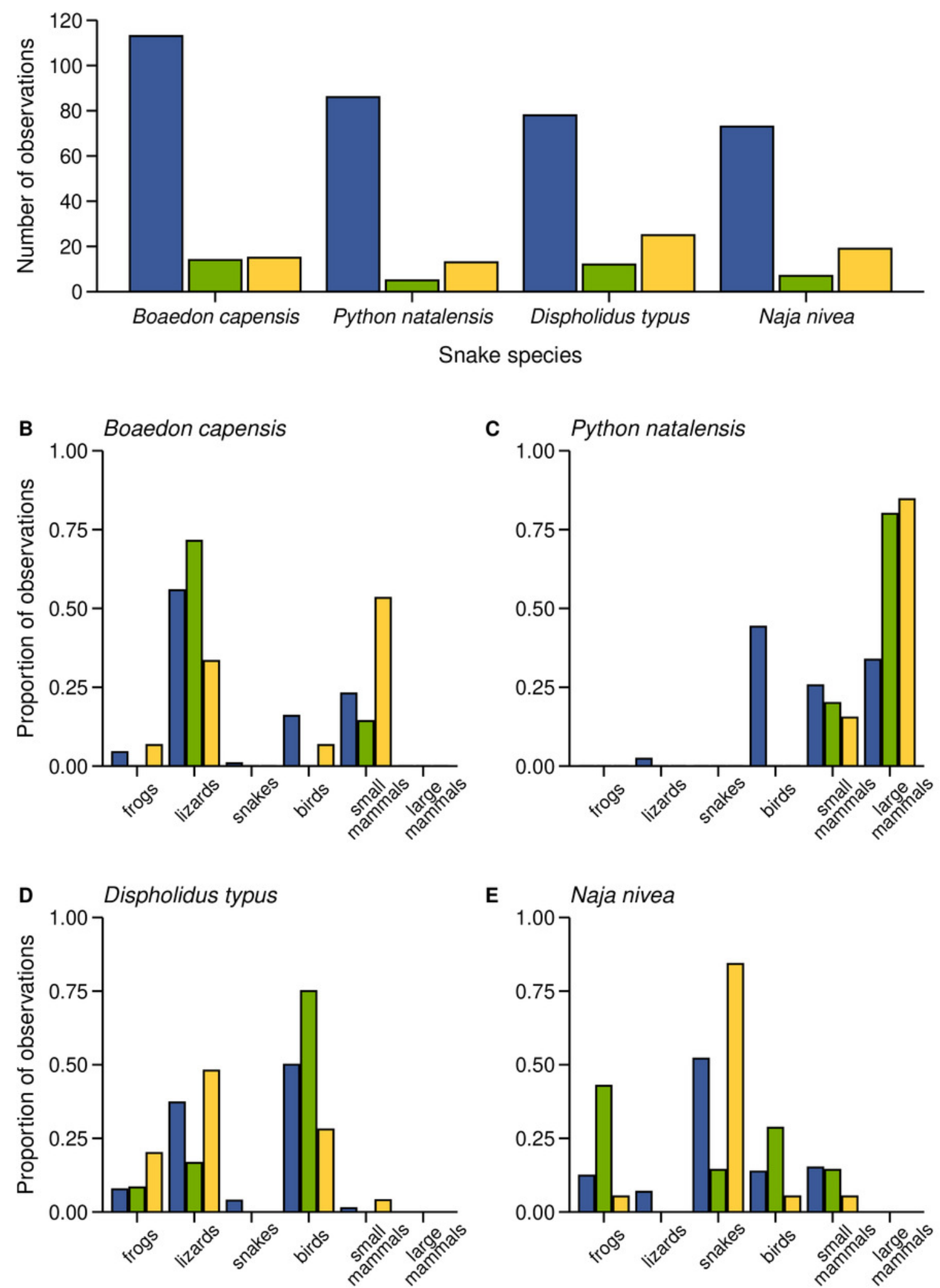

Prey identity

Prey identity 